\title{
P'urhepecha hyperraising to object: An argument for purely altruistic movement
}

\author{
Erik Zyman*
}

\begin{abstract}
Classical syntactic theory was designed to ensure that raising would be able to proceed out of infinitival clauses, but not out of finite clauses. However, it has since become clear that a number of languages in fact allow raising out of finite clauses (hyperraising). This paper argues that the Mexican isolate P'urhepecha-more specifically, the variety spoken on the island of Janitzio on Lake Pátzcuaro-allows hyperraising to object (cf. Bruening 2002, Tanaka 2002, Halpert \& Zeller 2015, Deal 2016), and develops an analysis of this phenomenon on which it involves two steps of purely altruistic (target-driven) movement-i.e., movement driven exclusively by a featural requirement of an attracting head. Alternative analyses of the phenomenon based on Greed (Chomsky 1995a, Bošković 2007, a.o.) or Labeling (Chomsky 2013, 2015, a.o.) are considered and shown to face serious problems. P'urhepecha hyperraising to object, then, sheds light on the driving force for movement: it provides an argument for Enlightened Self-Interest (Lasnik 1995, 2003, a.o.), the hypothesis that movement may be driven by a feature either of the moving element or (as here) of an attracting head. The phenomenon also narrows down the space of possibilities for understanding the $\mathrm{A} / \overline{\mathrm{A}}$-distinction.
\end{abstract}

Keywords. hyperraising to object; A/Ā-distinction; movement triggers; Greed; Enlightened Self-Interest; altruistic movement; Labeling; EPP subfeatures; P'urhepecha

1. Introduction. As is well known, raising in English and other familiar languages can proceed out of an infinitival, but not a finite, clause: compare $\boldsymbol{S h e}_{i}$ seems [INF _ $i$ to be happy] with * $\boldsymbol{S h e ~}_{k}$ seems [FIN _ $k$ is happy], and I believed him $_{i}$ incorrectly [ ${ }_{\mathrm{INF}}{ }_{i}$ i to be happy] with *I believed $\boldsymbol{h i m}_{k} / \boldsymbol{h e}_{k}$ incorrectly [FIN _ $k$ was happy]. Classical syntactic theory was designed to ensure this (see, e.g., the Tensed-S Condition (Chomsky 1973:238)). But as empirical work has progressed, it has become clear that some languages in fact make use of derivations along the lines of the two just starred (Tanaka 2002, Martins \& Nunes 2010, Carstens \& Diercks 2013, Halpert \& Zeller 2015, Deal 2016, Halpert 2016, Fong 2017, Petersen \& Terzi to appear, a.m.o.; see also Bruening 2002). On a traditional understanding of the $\mathrm{A} / \overline{\mathrm{A}}$-distinction, this is unexpected: finite clauses should allow $\overline{\mathrm{A}}$ - but not A-movement out of them. But that traditional understanding is being revisited and challenged (Chomsky 2008, Obata \& Epstein 2008, Safir 2015, van Urk 2015), and raising out of finite clauses provides one of the several motivations for this rethinking.

Against this background, the present paper argues that the Mexican language Janitzio P'urhepecha permits hyperraising to object (A-raising out of a finite clause which creates an object). It then develops an

*I am very grateful indeed to Antonio Reyes Justo, María Bárbara Bartolo López, Elvia Campos Talavera, Araceli de la Cruz Guzmán, Gloria de la Cruz Guzmán, Roque Eligio Hernández, Delfina Florentino López, Juan Gabriel Florentino, Esvelia Guzmán Reyes, María Estela Guzmán Reyes, and Olivia Guzmán Reyes for sharing with me their knowledge of and insights into their language. Many thanks also, for valuable discussion, to Jim McCloskey, Jorge Hankamer, Sandy Chung, Nathaniel Deutsch, Judith Aissen, Beatriz Arias Álvarez, Pranav Anand, Nate Arnett, James Collins, Amy Rose Deal, John Gluckman, Jane Grimshaw, Heidi Harley, Kyle Johnson, Nick Kalivoda, Itamar Kastner, Stefan Keine, Tyler Lemon, Travis Major, Ben Mericli, Jason Ostrove, Michelle Sheehan, Ivy Sichel, Adam Singerman, Maziar Toosarvandani, Susi Wurmbrand, the participants in the Fall 2015 Morphology seminar at UCSC, and attendees at NonFinite Subjects (University of Nantes, April 2016), the Workshop on the Languages of Meso-America (UCSC, December 2016), LSA 2017 (Austin, January 2017), and a talk at the University of Florida (February 2017). The usual disclaimers apply. This material is based upon work supported by the National Science Foundation Graduate Research Fellowship Program under Grant No. DGE-1339067. Any opinions, findings, and conclusions or recommendations expressed in this material are those of the author and do not necessarily reflect the views of the National Science Foundation. This research was also supported by two Summer Research Fellowships $(2014,2015)$ from the Institute for Humanities Research at UCSC. Author: Erik Zyman, University of California, Santa Cruz (ezyman@ucsc.edu). 
analysis of this type of raising - and specifically of the syntactic mechanisms that permit hyperraising in this language - and considers the theoretical implications of the phenomenon.

The paper is organized as follows. \$2 lays out the phenomenon, referring to it pretheoretically as "accusative + complementizer" (ACC-C). $\$ 3$ shows that the crucial accusative DP is in the matrix clause. $\$ 4$ argues that ACC-C is hyperraising, not prolepsis. $\$ 5$ argues against a third possible analysis of ACC-C, on which it is finite object control. \$6 presents an explicit analysis of ACC-C in Janitzio P'urhepecha, on which it involves two steps of purely altruistic (target-driven) movement. \$7 argues against alternative Greed- and Labeling-based analyses of the phenomenon. $\$ \mathbf{8}$ concludes.

2. The phenomenon. The data investigated here come from P'urhepecha, a Mexican isolate spoken mainly in the central-western state of Michoacán, and specifically from the variety spoken on the island of Janitzio on Lake Pátzcuaro (Janitzio P'urhepecha). P'urhepecha is an exclusively suffixing, agglutinating, headand dependent-marking language with relatively flexible constituent order (Foster 1969, a.m.o.).

In Janitzio P'urhepecha, the verb ueka- 'want' can select a (finite) subjunctive clause ${ }^{1}$ with a nominative subject ((1a)). (Nominative case is morphologically unmarked.) For some speakers, however, the embedded subject can alternatively surface to the left of the complementizer eska 'that', with accusative rather than nominative case ((1b)). (The crucial accusative DP is boxed throughout.)
a. Ueka-sïn- $\varnothing$-di=sï
eska Xumo u-a- $\varnothing-k a$
ma k'umanchikua.
want-HAB-PRS-IND3=pS that Xumo make-FUT-PRS-SBJV a house
'They want Xumo to build a house.'
b. Ueka-sin- $\varnothing$-di=sï Xumu-ni eska u-a- $\varnothing$-ka ma k'umanchikua.
want-HAB-PRS-IND3=pS Xumo-ACC that make-FUT-PRS-SBJV a house
'They want Xumo to build a house.'

The phenomenon illustrated in (1b) will for the time being be referred to pretheoretically as "accusative + complementizer" (ACC-C). ACC-C is possible only with certain matrix verbs. In addition to ueka- 'want' $((1 b))$, it can occur with uetarincha- 'need' ((2)) and, for some speakers, with mite- 'know' ((14) below).

(2) a. Uetarincha-sïn- $\varnothing$-ga=ni eska Elena k'uanatsinta-a- $\varnothing$-ka Xanichu-o. need-HAB-PRS-IND $1=1 \mathrm{sS}$ that Elena return-FUT-PRS-SBJV Janitzio-RESID 'I need Elena to return to Janitzio.' (RESID = residential case.)

b. Uetarincha-sïn- $\varnothing$-ga=ni Elena-ni eska k'uanatsinta-a- $\varnothing$-ka Xanichu-o. need-HAB-PRS-IND 1=1sS Elena-ACC that return-FUT-PRS-SBJV Janitzio-RESID 'I need Elena to return to Janitzio.'

3. The accusative DP is in the matrix. One question about $A C C-C$ that arises immediately is where the crucial accusative DP (henceforth $\mathrm{DP}_{\mathrm{ACC}}$ ) is. Simple examples of ACC-C such as (1b) and (2b) do not reveal whether $\mathrm{DP}_{\mathrm{ACC}}$ is in the matrix or at the left edge of the embedded clause (e.g., in [Spec,CP]). Fortunately, the two possibilities can be distinguished empirically. In particular, they make somewhat different predictions about where $\mathrm{DP}_{\mathrm{ACC}}$ should be able to occur with respect to matrix adverbials:

(3) a. Matrix hypothesis: It should perhaps be possible for $\mathrm{DP}_{\mathrm{ACC}}$ to precede a matrix adverbial that in turn precedes the embedded CP. (Cf. Postal 1974:146-154, Halpert \& Zeller 2015:485-486.)

b. Embedded hypothesis: $\mathrm{DP}_{\mathrm{ACC}}$ should not be able to precede such a matrix adverbial.

\footnotetext{
${ }^{1}$ In this language, the subjunctive mood is used in many or most types of embedded clauses, and may therefore be essentially a marker of subordination.
} 
The relevant sentences—-which feature the constituent order $\mathrm{DP}_{\mathrm{ACC}} \gg$ MATRIX ADVERBIAL $\gg \mathrm{CP}$-are relatively or even quite acceptable:

$$
\begin{aligned}
& \text { (?)Emilia ueka-sïn- } \varnothing \text {-di } \\
& \text { Emily want-HAB-PRS-IND3 Xumo-ACC heart-ACC with that help-FUT-PRS-SBJV } \\
& \text { pauani. } \\
& \text { tomorrow } \\
& \text { 'Emily wants Xumo with all her heart to help her tomorrow.' }
\end{aligned}
$$

This is strong evidence that $\mathrm{DP}_{\mathrm{ACC}}$ can be in the matrix. ${ }^{2}$

4. ACC-C is hyperraising, not prolepsis. Now that we know that $\mathrm{DP}_{\mathrm{ACC}}$ is in the matrix, a crucial question is how it gets there. Two possibilities are the following:

(5) a. Hyperraising hypothesis: The DP raises from within the embedded CP.

$$
\ldots\left[\begin{array}{c}
\mathrm{DP} \\
\uparrow
\end{array} \ldots[\mathrm{CP} \ldots \mathrm{DP} \ldots]\right.
$$

b. Prolepsis hypothesis: The DP is base-generated in the matrix and anaphorically linked to a pro in embedded subject position.

$$
\ldots \mathrm{DP}_{i} \ldots\left[\mathrm{CP} \ldots \operatorname{pro}_{i} \ldots\right]
$$

We now turn to three strands of evidence that show that the DP raises from within the embedded CP.

4.1. ESCAPE-HATCH BLOCKING. The hyperraising and prolepsis hypotheses make potentially different predictions about whether ACC-C should display an escape-hatch blocking effect:

(6) a. Hyperraising hypothesis: In raising into the matrix, the embedded subject DP should pass through the embedded [Spec,CP]. Therefore, it should perhaps be impossible to additionally extract another XP from the embedded CP. ${ }^{3}$

b. Prolepsis hypothesis: ACC-C should not interfere with extraction from the embedded CP.

Note in this connection that prolepsis in English is compatible with extraction from the embedded CP:

(7) What ${ }_{i}$ does Mike know (for sure) about Katie ${ }_{k}$ [CP that she $\mathbf{s}_{k}$ wants to do __ $\left.{ }_{i}\right]$ ?

ACC-C, it turns out, does display the escape-hatch blocking effect. Sentence (8a) shows that, when ACC-C does not occur, the wh-phrase ambe 'what' can be extracted from the embedded CP. In ( $8 \mathrm{~b}$ ), ACC-C has taken place, but interrogative $w h$-movement has not. In (8c), both have been attempted, and the result is highly degraded. ACC-C, then, cannot cooccur with interrogative $w h$-extraction from the embedded CP.

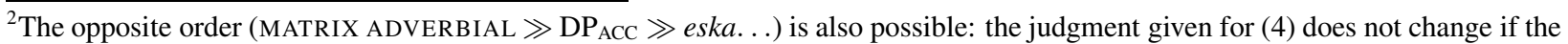
boxed $\mathrm{DP}_{\mathrm{ACC}}$ is placed to the immediate right of the boldfaced matrix adverbial. What is important here, though, is that (4) shows that $\mathrm{DP}_{\mathrm{ACC}}$ can be in the matrix.

${ }^{3}$ These predictions are being informally discussed here in terms of the traditional idea of [Spec,CP] as the CP "escape hatch," which should be "blocked" by the intermediate copy in this position of the hyperraising DP. However, the prediction is a bit different in Bare Phrase Structure (Chomsky 1995b), which is officially adopted here. Bare Phrase Structure rejects (as an undesirable stipulation) the older idea that every head projects a classical $\bar{X}$-theoretic template containing at most one specifier position. Therefore, if ACC-C is hyperraising, but some XP other than the hyperraising DP can somehow get to the CP phase edge, then it should be possible to extract them both after all. The predictions in (6) are still worth testing, though. If ACC-C is compatible with XP-extraction from the embedded CP, this will not help us choose between the two hypotheses. But if ACC-C blocks XP-extraction from the embedded $\mathrm{CP}$, this will support the hyperraising hypothesis, as well as the further conclusion that at most one XP can move to the CP phase edge (perhaps because the embedded C in ACC-C can bear at most one EPP subfeature; see $\S \S 6-7$ ).
} 
b. Uetarincha-sïn- $\varnothing$-di=sï Emilia-ni [CP eska pia-a- $\varnothing$-ka itsukua]. need-HAB-PRS-IND3=pS Emily-ACC [CP that buy-FUT-PRS-SBJV milk] 'They need Emily to buy milk.'

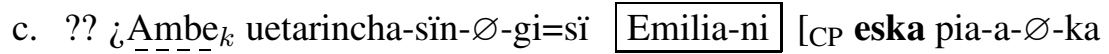
$k]$ ? what $_{k}$ need-HAB-PRS-INT=pS Emily-ACC [CP that buy-FUT-PRS-SBJV _ ${ }_{k}$ ] int. 'What do they need Emily to buy?' 4

4.2. INTERVENTION EFFECTS. The hyperraising and prolepsis hypotheses also make potentially different predictions about whether ACC-C should show intervention effects:

(9) a. Hyperraising hypothesis: ACC-C should perhaps be expected to show intervention effects, with $\mathrm{DP}_{\mathrm{ACC}}$ corresponding to the subject of the embedded $\mathrm{CP}$ and never to any lower argument. $^{5}$

b. Prolepsis hypothesis: ACC-C should not show intervention effects. $\mathrm{DP}_{\mathrm{ACC}}$ should be able to correspond to DPs within the embedded CP other than the highest subject.

ACC-C does display intervention effects:
a. Ueka-s̈̈n- $\varnothing$-ga=ni Elena-ni ${ }_{i} \quad$ [CP eska jananari-a- $\varnothing-k a$
Berta-ni]. want-HAB-PRS-IND $1=1 \mathrm{sS}$ Elena-ACC ${ }_{i}\left[\mathrm{CP}\right.$ that $\_i$ respect-FUT-PRS-SBJV Bertha-ACC $]$ 'I want Elena to respect Bertha.'
b. *Ueka-sïn- $\varnothing$-ga $=$ ni $\quad$ Berta-ni $k \quad\left[\right.$ cP eska Elena jananari-a- $\varnothing$-ka $\left.{ }_{k}\right]$. want-HAB-PRS-IND $1=1 \mathrm{sS}$ Bertha-ACC ${ }_{k}\left[\mathrm{CP}\right.$ that Elena respect-FUT-PRS-SBJV ${ }_{k}$ ] int. 'I want Elena to respect Bertha.'

4.3. ISLAND EFFECTS. Finally, the hyperraising and prolepsis hypotheses make different predictions about whether ACC-C should obey islands:

(11) a. Hyperraising hypothesis: ACC-C, being movement, should obey islands. (Cf. Bruening 2002, \$3.1.4; Fong 2017:2.)

b. Prolepsis hypothesis: ACC-C, a base-generated anaphoric dependency, should not obey islands.

Note that English prolepsis is not constrained by islands (e.g., relative-clause and adjunct islands):

(12) a. We want of this hypothesis ${ }_{i}$ that the predictions [RC it $_{i}$ makes] be empirically testable.

b. I know about Olivia ${ }_{k}$ that people tend to freak out [adjunct when she ${ }_{k}$ starts yodeling].

ACC-C, by contrast, does obey islands. It cannot cross the boundary of a relative-clause island:

\footnotetext{
${ }^{4}$ As pointed out to me by Amy Rose Deal, though, the embedded CP in German prolepsis structures behaves like a (weak) island (Salzmann to appear). The data in (8) could therefore be reconciled with the prolepsis hypothesis by analyzing ACC-C as Germanrather than English-style prolepsis. See $\S \S 4.2-4.3$, however, for more arguments that ACC-C is not prolepsis.

${ }^{5}$ This is predicted only if ACC-C_-more precisely, the first step therein—is A-movement (cf. Fido $i$ seems [_ i to have chased her] $\sim *$ She $e_{k}$ seems [Fido to have chased __ ${ }_{k}$ ]). Note that English prolepsis does not display intervention effects: Wayne said about the Doberman ${ }_{i}\left\{\right.$ that $_{i} \boldsymbol{t}_{i}$ had chased the principal / that the principal had chased $\left.\boldsymbol{i t}_{i}\right\}$.
} 
a. Ueka-sïn- $\varnothing$-ga $=$ ni eska k'uanatsenta-a- $\varnothing$-ka uariti enga minariku- $\varnothing-\varnothing-k a$

want-HAB-PRS-IND $1=1 \mathrm{sS}$ that return-FUT-PRS-SBJV woman $_{\text {RESP }}$ SUB meet-PFV-PRS-SBJV

juramuti-ni.

president-ACC

'I want the woman who knows the president to return.' (No ACC-C.)

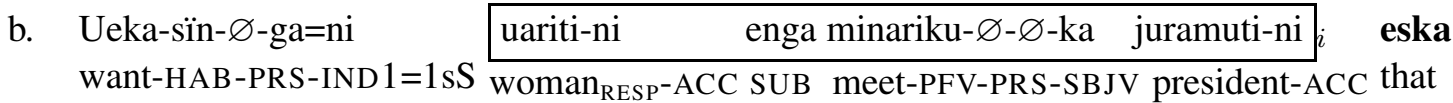
k'uanatsenta-a- $\varnothing-\mathrm{ka} \quad i$.

return-FUT-PRS-SBJV

'I want the woman who knows the president to return.' (ACC-C affects highest DP in eska-CP.)

c. *Ueka-sïn- $\varnothing$-ga $=$ ni juramuti-ni $k$ eska k'uanatsenta-a- $\varnothing$-ka uariti [RC enga

want-HAB-PRS-IND $1=1 \mathrm{sS}$ president-ACC ${ }_{k}$ that return-FUT-PRS-SBJV woman RESP $_{\text {[RC SUB }}$

minariku- $\varnothing-\varnothing-k a \quad \ldots k$ ].

meet-PFV-PRS-SBJV _ $k$ ]

int. 'I want the woman who knows the president to return.' (ACC-C can't cross RC boundary.)

Nor can ACC-C cross the boundary of an adjunct island:
a. Mite-sï- $\varnothing-\mathrm{ka}=\mathrm{ni}$
eska iamindu-eecha
know-PFV-PRS-IND $1=1 \mathrm{sS}$ that all-PL
kurandi-j- $\varnothing-k a=s i ̈ \quad$ [adjunct enga
jorhentperi uanda-na- $\varnothing-\mathrm{ka}]$.
teacher talk-DUR-PRS-SBJV]
'I know that everyone listens when the teacher's talking.' (No ACC-C.)
b. ?Mite-sï- $\varnothing-\mathrm{ka}=\mathrm{ni} \quad$ iamindu-eecha-ni ${ }_{i}$ eska _ $i$ kurandi-j- $\varnothing-\mathrm{ka}=\mathrm{si}$ [adjunct
know-PFV-PRS-IND $1=1 \mathrm{sS}$ all-PL-ACC ${ }_{i}$ that ${ }_{i}$ listen-HAB-PRS-SBJV=pS
enga jorhentperi uanda-na- $\varnothing-k a]$.
SUB teacher talk-DUR-PRS-SBJV]
'I know that everyone listens when the teacher's talking.' (ACC-C affects highest DP in CP.)
c. *Mite-sï- $\varnothing-\mathrm{ka}=\mathrm{ni} \quad$ jorhentperi-ni $k$ eska iamindu-eecha kurandi-j- $\varnothing-\mathrm{ka}=\mathrm{si}$
know-PFV-PRS-IND $1=1 \mathrm{sS}$ teacher- $\mathrm{ACC}_{k}$ that all-PL listen-HAB-PRS-SBJV=pS
[adjunct enga _ $\ldots$ uanda-na- $\varnothing$-ka].
SUB _ $k$ talk-DUR-PRS-SBJV]
int. $\approx$ 'I know about the teacher ${ }_{k}$ that everyone listens when (s)he's ${ }_{k}$ talking.'

To recapitulate, ACC-C involves escape-hatch blocking, shows intervention effects (a hallmark of A-movement), and obeys islands, supporting the hyperraising hypothesis over the prolepsis hypothesis.

5. ACC-C is hyperraising, not finite object control. The conclusion that ACC-C is hyperraising, however, has not yet been definitively established, because there is a third possible analysis that has to be considered: one on which ACC-C is finite object control (i.e., object control into a finite clause), as shown in (15).

$$
\ldots \mathrm{V} \mathrm{DP}_{i} \ldots\left[\mathrm{CP} \ldots \mathrm{PRO}_{i} \ldots\right]
$$

We now turn to two arguments that ACC-C really is hyperraising and not finite object control.

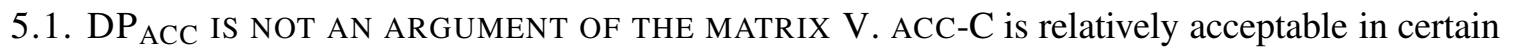
sentences in which $\mathrm{DP}_{\mathrm{ACC}}$ could not be reasonably analyzed as a thematic argument of the matrix V: 
(16) a. [Context: Near my house there's another, old house that blocks my view, and no one lives there.]
?Ueka-sïn- $\varnothing$-ga=ni inde-ni k'umanchikua-ni eska xembanta-na-a- $\varnothing$-ka. want-HAB-PRS-IND $1=1 \mathrm{sS}$ that MED -ACC house-ACC that destroy-PASS-FUT-PRS-SBJV 'I want that house to be destroyed.' (N.B. I don't want the house.)

b. [Context: In the park there's an old abandoned car that I think is really ugly.]

$\begin{array}{lll}\text { ?Ueka-sïn- } \varnothing \text {-ga=ni } & \text { ima-ni parikutarakua-ni eska pinande-a- } \varnothing \text {-ka. } \\ \text { want-HAB-PRS-IND } 1=1 \mathrm{sS} & \text { that } \text { thIST }_{\text {-ACC car-ACC }} \text { that disappear-FUT-PRS-SBJV }\end{array}$

'I want that car to disappear.' (N.B. I don't want the car.) ${ }^{6}$

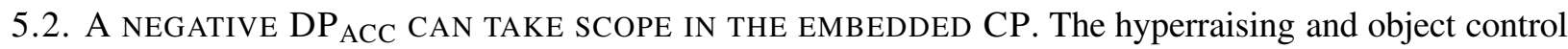
hypotheses make somewhat different predictions about where a negative $\mathrm{DP}_{\mathrm{ACC}}$ should be able to take scope:

(17) a. Hyperraising hypothesis: We may expect a negative $\mathrm{DP}_{\mathrm{ACC}}$ to be able to take scope within the embedded $\mathrm{CP}$ it raises from, and hence within the scope of the matrix V.

b. Finite object control hypothesis: A negative $\mathrm{DP}_{\mathrm{ACC}}$ is base-generated in the matrix, and should therefore be forced to take matrix scope.

Note that a negative object in an English object control structure obligatorily outscopes the matrix V:

(18) Unfortunately, Sophie persuaded no one ${ }_{i}\left[\mathrm{XP} \mathrm{PRO}_{i}\right.$ to go to the rock show].

$\checkmark$ no one $\gg$ persuade: 'There was no one who Sophie persuaded to go to the rock show.'

*persuade $\gg$ no one: *'Sophie brought it about by persuasion that [there was no one who went...].'

In ACC-C, a negative $\mathrm{DP}_{\mathrm{ACC}}$ apparently can take scope in the embedded $\mathrm{CP}$ (within the scope of matrix V):

(19) [Context: In a noisy, chat-filled library, a teacher who's trying to concentrate on her reading says.... $]^{7}$

(?) None-ni uetarincha-sïn- $\varnothing$-ga=ni eska uandana-a- $\varnothing$-ka. no.one-ACC need-HAB-PRS-IND1 1 1sS that talk-FUT-PRS-SBJV 'I need [(for) no one to talk].'

Sentence (19) is quite decently acceptable on the reading shown-one on which none 'no one' takes scope in the embedded CP, below uetarincha- 'need': 'I need [there to be no one who talks].' On the object control hypothesis, noneni 'no one' is generated in the matrix, and should therefore be forced to take matrix scope, above 'need' - yielding the reading 'There's no one who I need to talk'. But this would be an irrelevant and bizarre assertion for the teacher to make in the context given.

\footnotetext{
${ }^{6}$ There is a question as to why (16a-b) are merely reasonably acceptable and not perfect. One possibility is that, in each of them, the Accusative Nominal + CP string has an alternate parse as a relativization structure (e.g., 'that house that will be destroyed'). The likely existence of this parse does not threaten the argument from (16a-b) that ACC-C is not control, because the sentences would be infelicitous on the relativization parse in the contexts given, and therefore a hyperraising parse is needed to explain why they are reasonably acceptable. But although (16a-b) should be infelicitous on their relativization parse in the contexts provided, it could be that the existence of this parse adds a layer of complexity to the task of judging them, and it is this that resulted in their being judged less than fully acceptable.

${ }^{7}$ Negative objects move to a preverbal position in Janitzio P'urhepecha.
} 
Let us take stock. $\S 4$ showed that ACC-C is not prolepsis. In this section, evidence from $\theta$-relations and scope reconstruction (for negative $\mathrm{DP}_{\mathrm{ACC}}$ ) showed that $\mathrm{ACC}-\mathrm{C}$ is not object control. The hyperraising hypothesis, by contrast, accounts for all the data examined so far. ACC-C will therefore be referred to from now on as hyperraising to object (cf. Bruening 2002, Tanaka 2002, Halpert \& Zeller 2015, Deal 2016, a.o.).

6. Analysis. In order to determine what hyperraising to object in Janitzio P'urhepecha reveals about the mechanisms allowing hyperraising and, in particular, about the driving force for movement, we will need an explicit analysis of the phenomenon-which it is this section's task to provide.

6.1. HYPERRAISING TO OBJECT TARGETS A SPECIFIER OF vP. The structure of a finite clause in Janitzio $\mathrm{P}$ 'urhepecha is (in part) the following ("AdvP $\mathrm{M}_{\mathrm{M}}$ " = manner $\left.\operatorname{AdvP}\right):{ }^{8}$

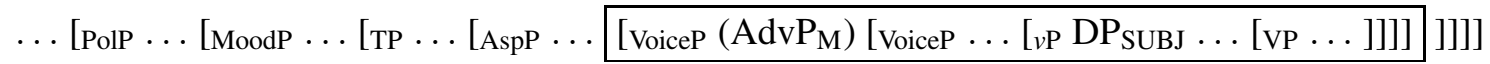

The verb word can surface in Voice, Asp, T, or Mood. The subject can appear in [Spec, $v \mathrm{P}]$, [Spec, VoiceP], [Spec,AspP], [Spec,TP], [Spec,MoodP] (this is somewhat tentative), or [Spec,PolP] (Zyman submitted). ${ }^{9}$

With this as background, consider the following sentence:

$$
\begin{aligned}
& \text { ?Mentku isi mintsita-ni jingoni ueka-sïn- } \varnothing \text {-di } \\
& \text { always thus heart-ACC with want-HAB-PRS-IND3 John-ACC Mary that } \\
& \text { jaruatpe-a- } \varnothing \text {-ka k'umanchikua-rhu. } \\
& \text { help-FUT-PRS-SBJV house-LOC } \\
& \text { 'Mary always wants John with all her heart to help out at home.' }
\end{aligned}
$$

Given the clause structure in (20), the derivation of (21) must be:

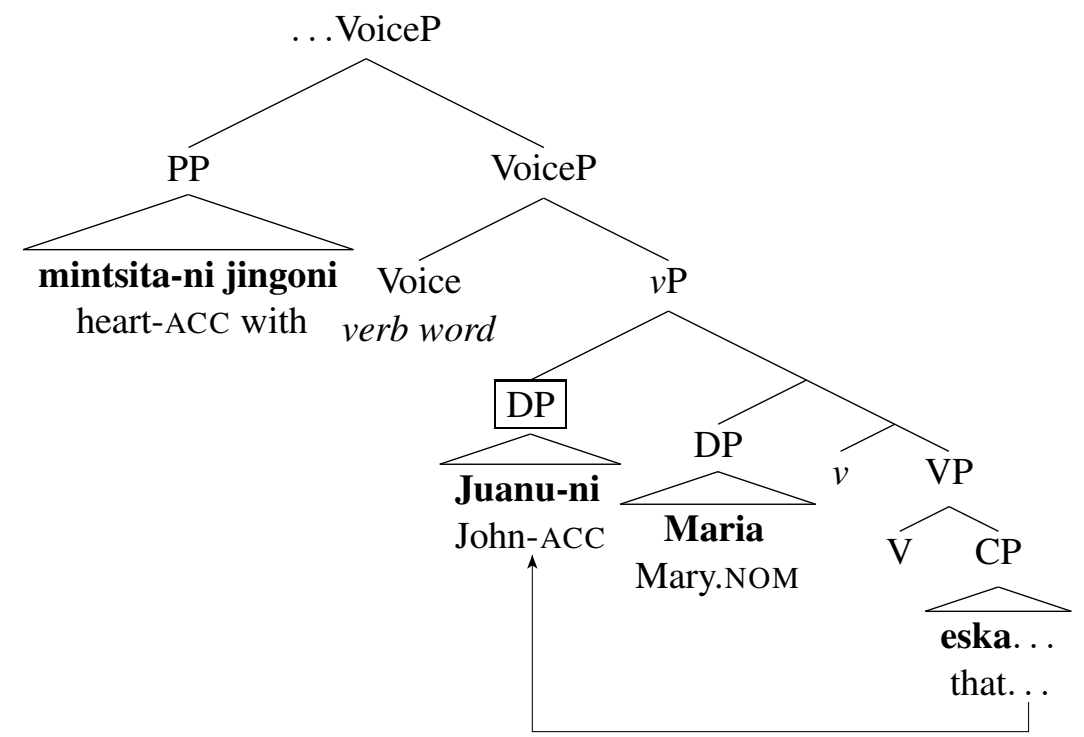

That is, hyperraising to object must target a specifier position of $v \mathrm{P}$. Now, in (22), the matrix subject (Maria) is externally merged with a projection of $v$, and then the hyperraising DP is internally merged. But if External and Internal Merge are really the same operation (Merge_Chomsky 2004), then, all else being

${ }^{8}$ This is slightly revised from Zyman submitted (§3). That paper argues for everything in (20), including the analysis of manner adverbials as VoiceP-adjuncts-except that it posits only a VoiceP but no separate $v$ P. The data given here, however, require positing both. To the degree that the analysis is successful, it supports the view that VoiceP and $v \mathrm{P}$ are separate in Janitzio P'urhepecha.

${ }^{9}$ A similar analysis of "prolific subject movement" of this type is argued for convincingly for Dholuo by Cable (2012). 
equal, it should alternatively be possible to internally merge the hyperraising DP and then externally merge the matrix subject, yielding the order MATRIX SUBJECT $\gg \mathrm{DP}_{\mathrm{ACC}}$. This is correct: ${ }^{10}$

\author{
(?)Mentku isï mintsita-ni jingoni ueka-sïn- $\varnothing$-di Maria Juanu-ni eska \\ always thus heart-ACC with want-HAB-PRS-IND3 Mary John-ACC that \\ jaruatpe-a- $\varnothing$-ka k'umanchikua-rhu. \\ help-FUT-PRS-SBJV house-LOC \\ 'Mary always wants John with all her heart to help out at home.' 11
}

6.2. ANALYSIS. Let us lay out our analysis of hyperraising to object in Janitzio P'urhepecha by deriving (23). First, the core of the embedded CP is built: ${ }^{12}$

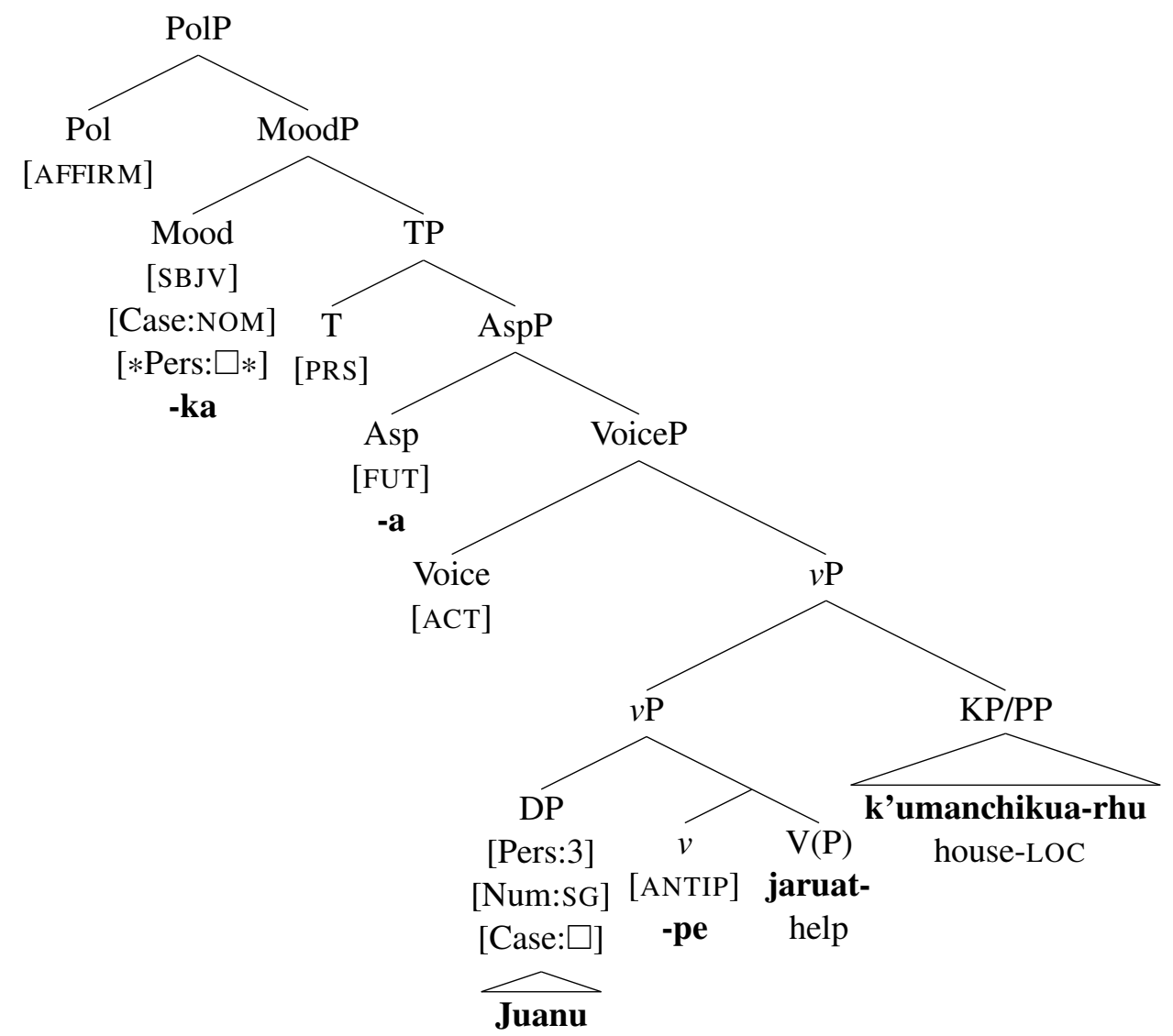

\footnotetext{
${ }^{10}$ This provides an argument against both Merge over Move (Chomsky 1995a, 2000) and Move over Merge (Shima 2000, Larson 2015). Alternatively, as pointed out to me by Maziar Toosarvandani, it could in principle be that the External and Internal Merge steps are rigidly ordered, but tucking-in (Richards 1997) can optionally occur in this case.

${ }^{11}$ Amy Rose Deal has proposed to me an alternative analysis (call it Analysis B) on which hyperraising targets not [Spec, $\left.v \mathrm{P}\right]$ but [Spec,VP] (cf. Deal 2016:6, (21)), accounting straightforwardly for the MATRIX SUBJECT $\gg$ DP $_{\text {ACC }}$ order in (23), and (21) is derived by optional scrambling of $\mathrm{DP}_{\mathrm{ACC}}$ from $[\mathrm{Spec}, \mathrm{VP}]$ to $[\mathrm{Spec}, v \mathrm{P}]$. As she points out, this would make it straightforward to capture the effect of V choice (the fact that hyperraising is possible only with certain Vs). Both analyses must "say something" to account for all the data: Analysis A (but not Analysis B) must capture the effect of V choice by positing that the hyperraising $v$ selects only certain Vs; Analysis B (but not Analysis A) must posit optional short scrambling. (The scrambling must target [Spec, $v \mathrm{P}$ ] specifically: attempting to move $\mathrm{DP}_{\mathrm{ACC}}$ in $(23) /(21)$ one specifier position higher, to [Spec, VoiceP]—the position immediately preceding the verb word-produces a highly degraded (“??”) result.) With those provisions made, both analyses are empirically adequate. I will continue to develop Analysis A here, but I note for reference that Analysis B seems equally viable.

${ }^{12}$ This discussion abstracts away from the derivational effects of the clause-internal phase, if there is one (e.g., $v \mathrm{P}$ or VoiceP). Also, the antipassive suffix -pe in jaruat-pe- 'help-ANTIP' is tentatively analyzed here as a $v$. None of this should affect the analysis.
} 
The subjunctive Mood head $-k a$ has an unvalued Person feature. ${ }^{13,14}$ It probes, finds [DP Juanu], uses its [Pers:3] feature to value its own Person feature, and values [DP Juanu]'s unvalued Case feature nominative.

Merged in next is the C eska 'that'. I claim that there are two versions of eska: one without and one with a feature $[* \mathrm{D} *]^{\mathrm{EPP}}$. In hyperraising to object, the version of eska bearing $[* \mathrm{D} *]^{\mathrm{EPP}}$ is chosen. It probes for a goal bearing the feature [D] (more precisely, [CAT:D]) and finds [DP Juanu], thereby satisfying its own [*D*] feature. This feature's EPP subfeature forces the goal of the Agree operation, [DP Juanu], to internally merge with the highest projection of eska (the traditional $\overline{\mathrm{C}}$ ):

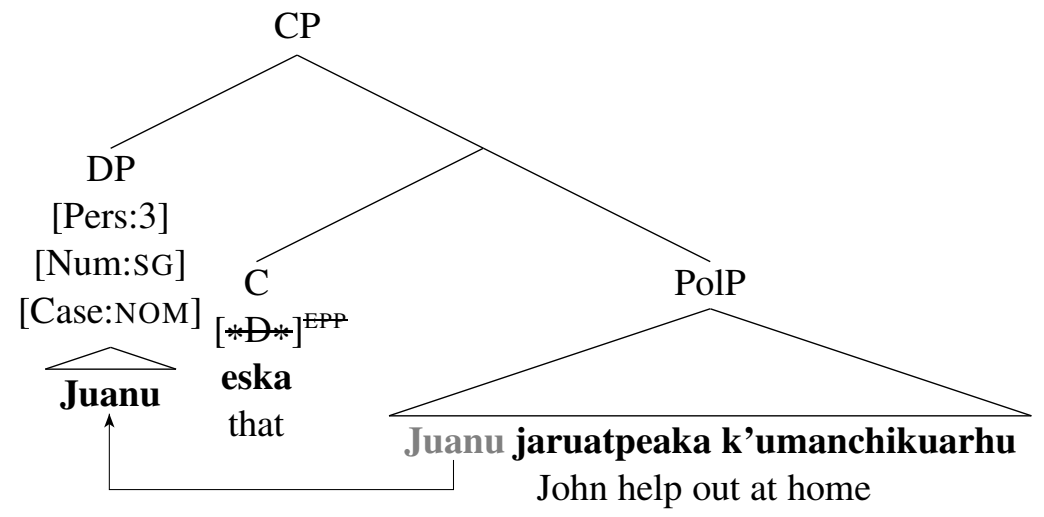

Since CP is a phase, eska is a phase head, so its complement (PolP) is spelled out. The highest copy of [DP Juanu] is on the phase edge, and hence still accessible. The derivation continues, yielding the following:

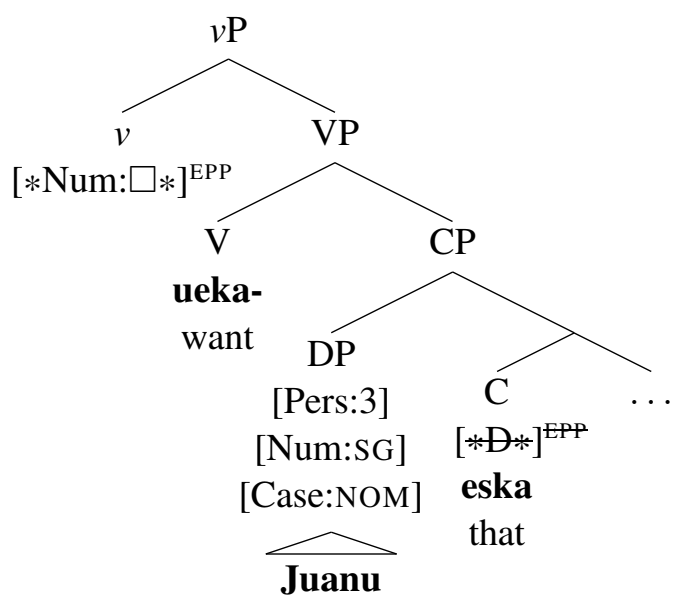

As shown in (26), the hyperraising $v$ selects the V ueka- 'want' (or another V compatible with hyperraising to object). This $v$ also bears an unvalued Number probe with an EPP subfeature. Therefore, $v$ probes its c-command domain, finds [DP Juanu], and uses its [Num:SG] feature to value its own Number feature singular. That is, $v$ is essentially an "object agreement" probe. ${ }^{15}$

\footnotetext{
${ }^{13}$ The basis for this assumption is the fact that the indicative Mood suffix is a portmanteau that also expones the person of the subject: $-k a(1 / 2) \sim-t i(3)(\rightarrow-g a,-d i$ immediately after $/ \mathrm{n} /)$. I assume for concreteness that the indicative Mood head not only agrees with the subject in person but also assigns it nominative Case, and that the subjunctive Mood head behaves identically, even though the latter always surfaces as $-k a(/-g a)$. Simplified person features such as [Pers:3] are used here for convenience.

${ }^{14}$ Following Heck and Müller 2007, features that trigger Agree are notated with stars- $[* \mathrm{~F} *]$-and unvalued features with a box: $[\mathrm{F}: \square]$. Departing from their notation, features that trigger Agree and bear an EPP subfeature are notated $[* \mathrm{~F} *]^{\mathrm{EPP}}$.

${ }^{15}$ The valued Number feature on $v$ can be exponed overtly. For the consultant who supplied these judgments, a plural DP $\mathrm{ACC}$ optionally triggers the appearance of the plural object agreement morpheme $-a$ in the matrix verbal complex; omitting this
} 
The valued Number feature's EPP subfeature forces the Agree goal, [DP Juanu], to internally merge with the highest projection of $v$ (the traditional $\bar{v}$ ):

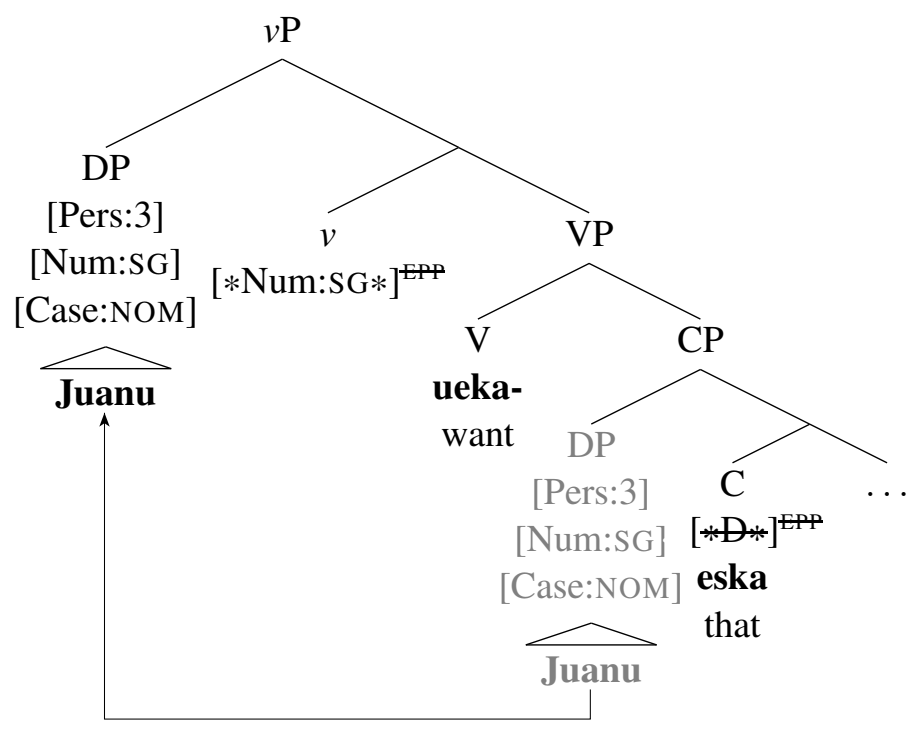

(The question of how the hyperraised DP ends up accusative is set aside here, ${ }^{16}$ since our main goal is to understand the precise mechanics of the movements.) Merged in next is the matrix subject (Maria):

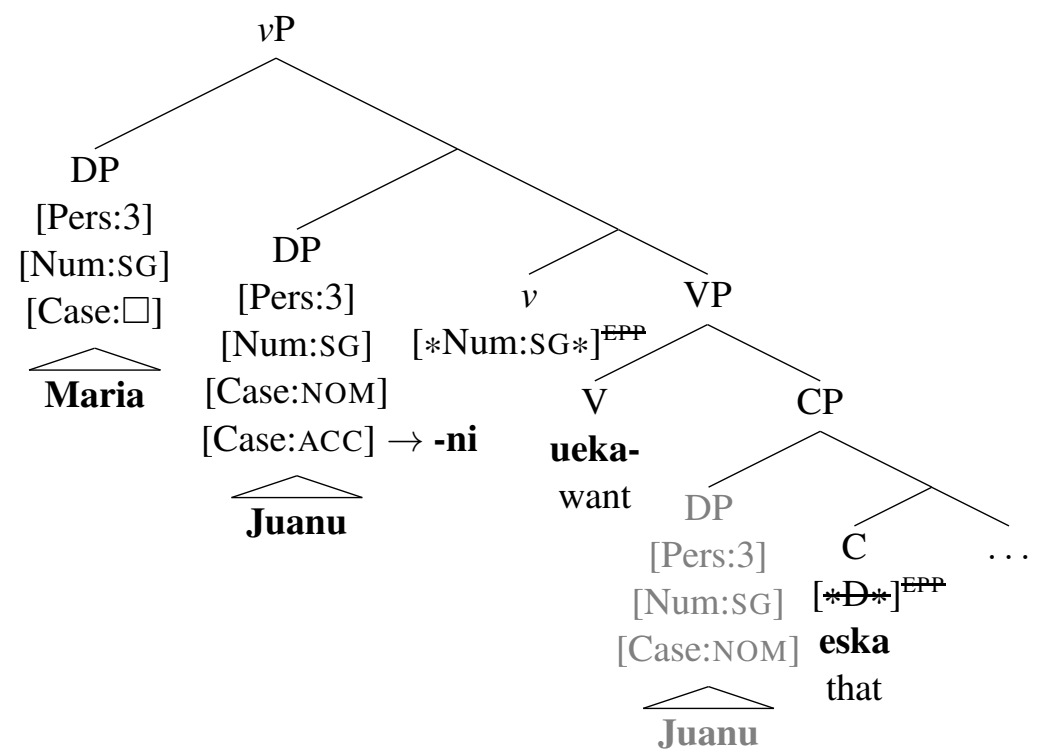

- $a$ produces a result which is still acceptable but marked by comparison ((1a) below). The same pattern obtains in an ordinary transitive clause ((1b) below).

(1) a. Ueka- ${ }^{\mathrm{M}}(\mathbf{a})-$ sïn- $\varnothing$-ga $=$ ni $\quad$ Maria-ni ka Klara-ni mintsita-ni jingoni eska pire-a- $\varnothing$-ka $=s i ̈$. want $^{\mathrm{M}}$ (pO)-HAB-PRS-IND 1 $=1 \mathrm{sS}$ Maria-ACC and Clara-ACC heart-ACC with that sing-FUT-PRS-SBJV=pS

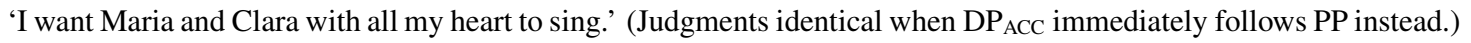

b. Uitsindekua exe- ${ }^{\mathrm{M}}(\mathbf{a})-\mathrm{si}-\varnothing-\mathrm{ka}=\mathrm{ni} \quad$ Xumu-ni ka Axuni-ni. yesterday see- $^{\mathrm{M}}(\mathrm{pO})$-PFV-PRS-IND $1=1 \mathrm{sS}$ Xumo-ACC and Axuni-ACC 'Yesterday I saw Xumo and Axuni.'

${ }^{16}$ Three possibilities, schematically described: 1) case stacking, 2) case overwriting, 3) dependent case assignment (without DP relicensing) (Fong 2017:8-9). 
The matrix $v \mathrm{P}$ merges with Voice, forming a VoiceP, to which the PP mintsitani jingoni 'with all her heart' left-adjoins. Later, Maria values the Person feature of matrix Mood, and receives nominative in return.

6.3. Crosslinguistic variation. On this analysis, what is special about Janitzio P'urhepecha that permits hyperraising to object in this language is that it allows a certain $\mathrm{C}$ (eska 'that') to bear a feature $[* \mathrm{D} *]^{\mathrm{EPP}}$, and allows (at least the hyperraising) $v$ to bear a feature $[* \mathrm{Num}: \square *]^{\mathrm{EPP}}$. In languages like English, by contrast, no $\mathrm{C}$ bears $[* \mathrm{D} *]^{\mathrm{EPP}}$, so hyperraising cannot get off the ground. The difference between hyperraising and nonhyperraising languages, then, resides in properties of particular lexical items. The analysis is thus compatible with the Borer-Chomsky Conjecture (cf. Baker 2008:353).

7. Against Greed- and Labeling-based alternatives. Consider again how a hyperraising-to-object sentence in Janitzio P' urhepecha is derived on this analysis:

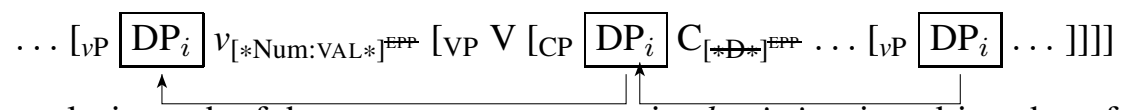

On this analysis, each of the two movement steps is altruistic-i.e., driven by a featural requirement of an attracting head. (More precisely, each of the two movements is driven by an EPP subfeature of a feature of an attracting head.) But there would appear to be two salient alternatives. Rather than being altruistic, these movement steps could be greedy or Labeling-driven. The three hypotheses under consideration about what the driving force for movement is are laid out more explicitly below.

a. Greed: A constituent moves to satisfy a feature of its own.

(Chomsky 1995a:201; Bošković 1995, 2002, 2007; Grohmann, Drury, \& Castillo 2000; Harwood 2015:528, fn. 8; Holmberg, Sheehan, \& van der Wal 2016:11, a.o.)

b. Enlightened Self-Interest: A constituent moves to satisfy a feature of its own (greedy movement) or a feature of the head to whose specifier it moves (altruistic movement). (Chomsky 1995a:297, 2000, 2001, 2004, 2008, Lasnik 1995, 2003, McCloskey 2001, Bošković 2004 [appendix], Cable 2012, Ostrove 2016, 2017, a.o.; see also Nunes 2016)

c. Labeling: A constituent moves so that every relevant constituent in the structure can receive a label from the syntactic Labeling Algorithm.

(Chomsky 2013, 2015, Ott 2015, Rizzi 2015, Smith 2015, Bošković to appear, a.o.)

The following three subsections argue that P'urhepecha hyperraising to object is neither greedy nor Labeling-driven.

7.1. Alternative A: CASE-DRiven GREedy movement. If hyperraising to object is greedy, it is driven by a feature of the raising DP. A natural possibility is that the DP raises to get Case. It receives accusative Case in the matrix (plausibly from $v$ ), and consequently surfaces bearing the accusative case morpheme $-n i$.

Assuming that nominative Case is assigned by Mood in Janitzio P'urhepecha (fn. 13), it would therefore have to be posited that the subjunctive Mood head $-k a$ only optionally bears a [Case:NOM] feature that can Case-license the embedded subject. However, embedded finite CPs whose subjects hyperraise are otherwise identical to embedded finite CPs whose subjects do not hyperraise (and consequently bear nominative case) ((1-2)), which makes the Case-based analysis look artificial. (See also Deal 2016:7 and Halpert 2016:187 for arguments that hyperraising is not Case-driven in Nez Perce or Zulu either.)

Even worse for the Case-based analysis, there is evidence that nominative Case is in fact always available in embedded finite CPs in Janitzio P'urhepecha. In hyperraising to object, $\mathrm{DP}_{\mathrm{ACC}}$, though accusative, can be linked to a nominative floated quantifier in the embedded CP: 


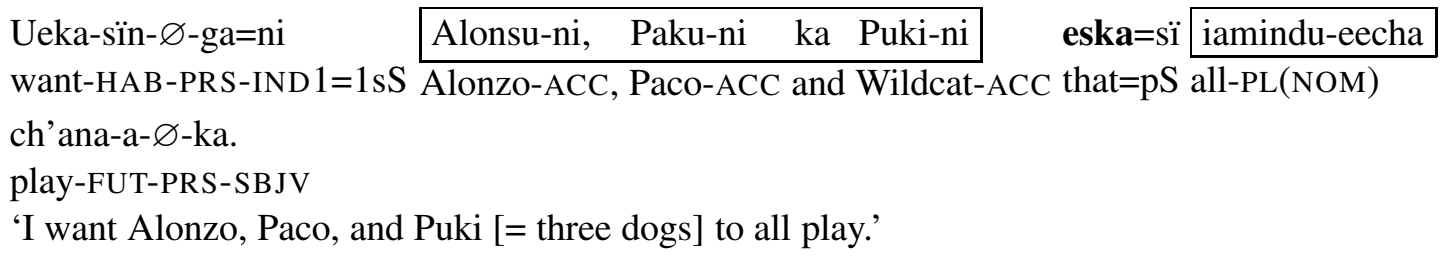

Regardless of whether Janitzio P'urhepecha floated quantifiers are stranded adnominal elements (as argued in Zyman submitted and Bošković to appear) or clause-level adverbials, the acceptability of sentences like (31) strongly suggests that nominative Case is available in the embedded CP in hyperraising to object. ${ }^{17,18}$

\subsection{Alternative B: Non-CASE-DRiven GReEDy movement. There is, however, a second} Greed-based analysis to consider: one on which the feature driving the movement is not a Case feature.

Bošković (2007) argues for an analysis of movement on which all movement is greedy. In his system, not only does every probe bear an unvalued feature, but also, conversely, every element bearing an unvalued feature (e.g., a DP with an unvalued Case feature) acts as a probe. If (and only if) an element bearing an unvalued feature cannot value it under Agree from where it is (by probing its c-command domain), it moves to a c-commanding position and tries to value it under Agree from there.

Let us attempt to extend this analysis to hyperraising to object in Janitzio P'urhepecha. Because a hyperraising DP in this language ends up in a matrix [Spec, $v \mathrm{P}]$, we could posit that a $\mathrm{D}$ in Janitzio P'urhepecha (and, derivatively, the DP it heads) can optionally bear a feature [uv], and it is this feature that drives hyperraising to object. ${ }^{19}$ On this analysis, hyperraising to object would be derived as follows. An embedded subject DP bearing $[u v]$ moves to [Spec,CP], the CP phase edge position. (If it doesn't, it will be spelled out with its $[u v]$ unvalued, causing a crash.) It then moves to a matrix [Spec, $v \mathrm{P}]$. Once there, it c-commands the matrix $v$. It can therefore value its $[u v]$ feature under Agree, and the derivation converges.

There are, however, two major problems with this analysis. First, a $[u v]$ feature could not cause an embedded subject to raise into the matrix, because the embedded $\mathrm{CP}$ also contains a $v$. From the embedded external argument base position ([Spec, $v \mathrm{P}]$ ), the embedded subject would c-command the embedded $v$; it would therefore not have to move at all to satisfy its $[u v]$ feature. When the embedded subject was base-generated in an internal argument position, satisfying the $[u v]$ feature would only require moving to an embedded $[\mathrm{Spec}, \nu \mathrm{P}]$. Further movement (into the matrix) would be unmotivated and therefore impossible.

Even if that problem could be dealt with somehow, a second problem would remain. If a $\mathrm{D}(\mathrm{P})$ could optionally bear $[u v]$, then, in some derivations, $[u v]$ would show up on the embedded object and not the embedded subject. Then, the object would hyperraise into the matrix. Hyperraising to object would thus be predicted not to show intervention effects (a hallmark of A-movement-type locality), contrary to fact ( 4.2 ).

7.3. Alternative C: Labeling-Driven movement. A third possible alternative analysis is one on which hyperraising to object is indirectly driven by the Labeling Algorithm (Chomsky 2013, 2015, a.o.).

\footnotetext{
${ }^{17}$ As pointed out to me by Bern Samko, a defender of the Case-based analysis could argue that the embedded CP in hyperraising to object is always nominative-deficient, and the nominative case on a floated quantifier like iamindueecha 'all' in (31) is a default case. But this would raise the question of why the associate of the floated quantifier does not also receive default nominative case, rendering hyperraising to object unnecessary (hence, by hypothesis, impossible; cf. Bošković \& Messick to appear), particularly given that a floated quantifier in Janitzio P'urhepecha obligatorily matches its associate in case (Zyman submitted, §5).

${ }^{18}$ Sentences like (31) also provide evidence that the Activity Condition is not an inherent, universal constraint on Agree (contra Chomsky 2000, 2001). (For other arguments against the Activity Condition, see Nevins 2004; see also Halpert 2016.) The floated quantifier shows that nominative Case is available in the embedded $\mathrm{CP}$, suggesting strongly that the embedded subject receives nominative Case as usual. (Indeed, how would this be prevented, since nominative Case is available?) But this DP is still able to hyperraise and enter into further A-relations: it can trigger plural "object agreement" in the matrix, and it receives (additional) accusative Case. From the standpoint of our analysis, on which P'urhepecha hyperraising to object is altruistic movement, this is a welcome result, since, as pointed out by Bošković (2002:175) and Bošković and Messick (to appear), subjecting supposedly altruistic (target-driven) movement to the Activity Condition essentially smuggles Greed back in through the back door.

${ }^{19}$ This is conceptually less attractive than the Case-based Greed analysis (§7.1), but still implementable.
} 
Descriptively speaking, hyperraising to object is optional. It is thus unlikely that it occurs to solve a labeling problem arising in the embedded $\mathrm{CP}$ - e.g., to allow labeling of a (problematically symmetrical) XP-YP structure with no feature sharing. Instead, let us try to adapt to the hyperraising case Chomsky's (2015) analysis of subject-raising to [Spec,TP] in English. Chomsky proposes that in English, but not in Italian, T is too "weak" to label its projections (henceforth simply weak), and must therefore be reinforced by raising the most prominent DP to "[Spec,TP]" (using the term Spec only for convenience). When this happens, the features shared by the DP and T ( $\phi$-features) can label the traditional "TP" $\langle\phi, \phi\rangle$. Returning to hyperraising to object, we could posit that the hyperraising $v_{[* N u m: \square *]}$ comes in two versions in the lexicon, one strong and one weak. ${ }^{20}$ When the weak one is chosen, the matrix " $\nu \mathrm{P}$ " will be successfully labeled only if a DP (which also bears a [Num] feature) raises to a matrix " [Spec, $v \mathrm{P}]$." When the embedded subject DP raises to a matrix "[Spec, $v \mathrm{P}]$," it and $v$ share a feature-[Num]—-so the " $v \mathrm{P}$ " can be labeled $\langle$ Num,Num $\rangle$.

This analysis too faces problems. First, the assumption that the hyperraising $v$ (which is silent) comes in two versions, one of which is too weak to label its projections, is stipulative. Chomsky's (2015) proposal that English $\mathrm{T}$ is weak but Italian $\mathrm{T}$ is strong for labeling purposes ties this putative difference to the traditional notion of richness of agreement (Rizzi 1982). Whether this will prove tenable is an open question, but at least the analysis ties the putative labeling-strength difference between English and Italian $\mathrm{T}$ to something observable; this is not possible in the case of the putative labeling-strength difference in Janitzio P'urhepecha. Secondly, Chomsky (2015) proposes that V is really a categoryless root R (see his paper for references), and although $\mathrm{R}$ is weak, $\mathrm{R}$-to- $v$ raising produces an $\mathrm{R}-v$ complex which is strong. If this is so, then it cannot be claimed that a certain $v$ in Janitzio P'urhepecha is weak, because $\mathrm{R}$ raises to $v$ in this language (cf. Zyman submitted, §3; note that $v$-to-Voice raising carries $\mathrm{R}$ along in (21-23)). ${ }^{21}$

8. Conclusion. This paper has argued that some speakers of Janitzio P'urhepecha allow hyperraising to object (cf. Bruening 2002, Tanaka 2002, Halpert \& Zeller 2015, Deal 2016, a.o.). The Janitzio P'urhepecha case joins a growing body of evidence that hyperraising is in fact possible in natural languages, indicating that the theory of grammar should not exclude this type of derivational path after all.

Hyperraising to object in Janitzio P'urhepecha was analyzed above as involving two steps of purely altruistic movement-i.e., movement driven exclusively by a featural requirement of an attracting head. If this analysis is on the right track, it strongly supports the hypothesis known as Enlightened Self-Interest (Lasnik 1995, 2003, a.o.) —namely, that movement may be driven either by a feature of the moving element or, as here, by a feature of an attracting head. (Alternative Greed- and Labeling-based analyses of P’urhepecha hyperraising to object, by contrast, face serious problems, as shown in §7.)

The analysis also contributes to narrowing down the space of possibilities for understanding the $\mathrm{A} / \overline{\mathrm{A}}$-distinction. P'urhepecha hyperraising to object suggests that an approach to the distinction on which [Spec,CP] is invariably an $\overline{\mathrm{A}}$-position, and an element that moves there cannot enter into further A-relations, is untenable. By contrast, a featural analysis of A/Ā-effects-on which A- and $\bar{A}$-effects are consequences of the presence of different types of features on particular functional heads (van Urk 2015, Fong 2017)—looks much more promising. If a language allows the feature [*D* ${ }^{\mathrm{EPP}}$ to appear not (only) on functional heads in the inflectional layer of the clause (cf. Rizzi 1997:281) but also on a finite C-a

\footnotetext{
${ }^{20}$ On the analysis being considered, the hyperraising $v_{[* N u m: \square *]}$ does not bear an EPP subfeature, since the analysis attempts to attribute to the Labeling Algorithm the effects ascribed to EPP subfeatures on other analyses (specifically, analyses on which movement is feature-driven and can be altruistic). See Boeckx 2010 for relevant discussion.

${ }^{21}$ It is worth noting that subjects in Janitzio P'urhepecha pose problems for the Labeling framework even independently of hyperraising. In this language, the subject can stay in situ, in [Spec, $v \mathrm{P}]((21),(23))$. This yields an XP-YP structure. Hence, " $v \mathrm{P}$ ” in these cases should be unlabelable, unless $v$ and the subject DP share a feature that can label " $v \mathrm{P}$," but there does not seem to be evidence for this. When the subject DP moves to [Spec,MoodP], the resulting XP-YP structure is unproblematic: Mood agrees with the subject in person, so "MoodP" can be labeled 〈Pers,Pers〉. But an XP-YP structure is also formed when the subject moves to [Spec,VoiceP], [Spec,AspP], [Spec,TP], or [Spec,PolP] (Zyman submitted, §4.1), and in these cases, there is no overt feature sharing. The relevant maximal projections ("VoiceP," "AspP," "TP," and "PolP") could be rendered labelable by positing covert feature sharing, but such a move would surely make Labeling analyses unfalsifiable in general.
} 
possibility which, crucially, nothing in the current theory rules out - then we should expect that language to allow A-raising out of finite CPs. Hyperraising to object, then-along with hyperraising to subject-ceases to be an anomaly and is revealed instead to be in line with theoretical expectation.

\section{References}

Baker, Mark C. 2008. "The macroparameter in a microparametric world.” In The Limits of Syntactic Variation, ed. T. Biberauer. Amsterdam: John Benjamins. 351-73.

Boeckx, Cedric. 2010. "A tale of two minimalisms: Reflections on the plausibility of crash-proof syntax. .." In Exploring Crash-Proof Grammars, ed. M. T. Putnam. Amsterdam: John Benjamins. 89-104.

Bošković, Željko. 1995. "Case Properties of Clauses and the Greed Principle.” Studia Linguistica 49: 32-53.

Bošković, Željko. 2002. “A-Movement and the EPP.” Syntax 5.3: 167-218.

Bošković, Željko. 2004. "Be Careful Where You Float Your Quantifiers.” NLLT 22.4: 681-742.

Bošković, Željko. 2007. "On the Locality and Motivation of Move and Agree: An Even More Minimal Theory." Linguistic Inquiry 38.4: 589-644.

Bošković, Željko. To appear. "On movement out of moved elements, labels, and phases." Linguistic Inquiry. Manuscript available online at http://ling.auf.net/lingbuzz/002851

Bošković, Željko and Troy Messick. To appear. "Derivational Economy in Syntax and Semantics.” In Oxford Research Encyclopedia of Linguistics. Ed. M. Aronoff. Oxford University Press.

Bruening, Benjamin. 2002. "Raising to Object and Proper Movement." Ms., University of Delaware. http:// udel.edu/ bruening/Downloads/RTO1.pdf

Cable, Seth. 2012. "The optionality of movement and EPP in Dholuo." NLLT 30: 651-97.

Carstens, Vicki and Michael Diercks. 2013. "Parameterizing Case and Activity: Hyper-raising in Bantu." In Proceedings of NELS 40. Ed. S. Kan, C. Moore-Cantwell, and R. Staubs. Amherst: GLSA. 99-118.

Chomsky, Noam. 1973. "Conditions on Transformations." In A Festschrift for Morris Halle. Eds. S. R. Anderson and P. Kiparsky. New York: Holt, Rinehart and Winston. 232-286.

Chomsky, Noam. 1995a. The Minimalist Program. Cambridge, MA: MIT Press.

Chomsky, Noam. 1995b. "Bare Phrase Structure." In Evolution and Revolution in Linguistic Theory: Studies in Honor of Carlos P. Otero. Eds. H. Campos and P. Kempchinsky. D.C.: Georgetown UP. 51-109.

Chomsky, Noam. 2000. "Minimalist inquiries: the framework." In Step by Step: Essays on Minimalist Syntax in Honor of H. Lasnik. Ed. R. Martin, D. Michaels, J. Uriagereka. Cambridge: MIT Press. 89-155.

Chomsky, Noam. 2001. "Derivation by Phase." In Ken Hale: A Life in Language. Ed. M. Kenstowicz. Cambridge, MA: MIT Press. 1-52.

Chomsky, Noam. 2004. "Beyond Explanatory Adequacy." In The Cartography of Syntactic Structures, Vol. 3. Structures and Beyond. Ed. A. Belletti. Oxford: Oxford University Press. 104-31.

Chomsky, Noam. 2008. “On Phases.” In Foundational Issues in Linguistic Theory: Essays in Honor of JeanRoger Vergnaud. Eds. R. Freidin, C. Peregrín Otero, M. L. Zubizarreta. Cambridge: MIT P. 133-166.

Chomsky, Noam. 2013. "Problems of projection." Lingua 130: 33-49.

Chomsky, Noam. 2015. "Problems of projection: Extensions." In Structures, Strategies and Beyond: Studies in honour of Adriana Belletti. Eds. E. Di Domenico, C. Hamann, and S. Matteini. Amsterdam/Philadelphia: John Benjamins. 3-16.

Deal, Amy Rose. 2016. "Covert hyperraising to object.” Handout from NELS 47, UMass Amherst.

Fong, Suzana. 2017. "Getting out of a finite CP: an analysis of hyper-raising." Handout from ECO-5, UConn.

Foster, Mary LeCron. 1969. The Tarascan Language. Berkeley: University of California.

Grohmann, Kleanthes K., John Drury, and Juan Carlos Castillo. 2000. "No More EPP." In Proceedings of WCCFL 19. Eds. R. Billerey and B. D. Lillehaugen. Somerville, MA: Cascadilla Press. 153-166.

Halpert, Claire and Jochen Zeller. 2015. "Right dislocation and raising-to-object in Zulu." The Linguistic Review 32.3: 475-513. 
Halpert, Claire. 2016. "Raising Parameters." In Proceedings of WCCFL 33. Eds. K. Kim et al. Somerville, MA: Cascadilla Proceedings Project. 186-195.

Harwood, William. 2015. "Being progressive is just a phase: celebrating the uniqueness of progressive aspect under a phase-based analysis." Natural Language and Linguistic Theory 33: 523-73.

Heck, Fabian, and Gereon Müller. "Extremely Local Optimization." In Proceedings of WECOL 26. Eds. E. Bainbridge and B. Agbayani. Fresno, CA: California State University. 170-183.

Holmberg, Anders, Michelle Sheehan, and Jenneke van der Wal. 2016. "Movement from the double object construction is not fully symmetrical." Ms., Newcastle University/University of Cambridge, Anglia Ruskin University, and Harvard University. http://ling.auf.net/lingbuzz/003075

Larson, B. 2015. "Minimal search as a restriction on Merge." Lingua 156: 57-69.

Lasnik, Howard. 1995. "Case and Expletives Revisited: On Greed \& Other Human Failings.” LI 26: 615-33.

Lasnik, Howard. 2003. "Last resort and attract F." In Minimalist Investigations in Linguistic Theory. London: Routledge. 22-41.

Martins, Ana Maria and Jairo Nunes. 2010. "Apparent Hyper-raising in Brazilian Portuguese: Agreement with Topics across a Finite CP.” In The Complementizer Phase: Subjects and Operators. Ed. E. P. Panagiotidis. Oxford: Oxford University Press. 143-163.

McCloskey, James. 2001. "The morphosyntax of WH-extraction in Irish.” J. of Linguistics 37.1: 67-100.

Nevins, Andrew. 2004. "Derivations without the Activity Condition." MITWPL 49: 287-310.

Nunes, Jairo. 2016. "On the locus and licensing of edge features." Ms., University of São Paulo. http://www. researchgate.net/publication/310156524_On_the_locus_and_licensing_of_edge_features

Obata, Miki and Samuel David Epstein. 2008. "Deducing Improper Movement from Phase-Based C-to-T Phi Transfer: Feature-Splitting Internal Merge.” In Proceedings of WCCFL 27. Ed. N. Abner and J. Bishop. Somerville, MA: Cascadilla Proceedings Project. 353-360.

Ostrove, Jason. 2016. "Non-Uniform Case Assignment in Scottish Gaelic." Handout from Arizona Linguistics Circle, University of Arizona, Tucson. http://people.ucsc.edu/ jostrove/alc10.pdf

Ostrove, Jason. 2017. "WH-Movement in San Martín Peras Mixtec." Handout from the Workshop on the Languages of Meso-America (WLMA), University of California, Santa Cruz.

Ott, Dennis. 2015. “Symmetric Merge \& Local Instability: Evidence from Split Topics.” Syntax 18: 157-200.

Petersen, Carolina and Arhonto Terzi. To appear. "Hyperraising and locality: a view from Brazilian Portuguese and Greek." Proceedings of CLS 50.

Postal, Paul M. 1974. On Raising. Cambridge, MA: MIT Press.

Richards, Norvin. 1997. What Moves Where When in Which Language? Diss. MIT.

Rizzi, Luigi. 1982. Issues in Italian Syntax. Dordrecht: Foris.

Rizzi, Luigi. 1997. "The Fine Structure of the Left Periphery." In Elements of Grammar: A Handbook of Generative Syntax. Ed. L. Haegeman. Dordrecht: Kluwer. 281-337.

Rizzi, Luigi. 2015. "Notes on labeling and subject positions." In Structures, Strategies and Beyond: Studies in honour of Adriana Belletti. Eds. E. Di Domenico, C. Hamann, and S. Matteini. Amsterdam/Philadelphia: John Benjamins. 17-46.

Safir, Ken. 2015. "The A-/A'-distinction as an epiphenomenon.” Ms., Rutgers University.

Salzmann, Martin. To appear. "Prolepsis." In The Companion to Syntax, 2nd Edition. Eds. M. Everaert and H. van Riemsdijk. Wiley-Blackwell.

Shima, Etsuro. 2009. "A Preference for Move over Merge.” Linguistic Inquiry 31.2: 375-385.

Smith, Ryan Walter. 2015. "A Labeling Approach to Constraints on Coordinate Structure Syntax." Ms., University of Arizona. http://ryanwaltersmith.wixsite.com/home/papers

Tanaka, Hidekazu. 2002. "Raising to Object out of CP." Linguistic Inquiry 33.4: 637-652.

van Urk, Coppe. 2015. A uniform syntax for phrasal movement: A case study of Dinka Bor. Diss. MIT.

Zyman, Erik. Submitted. “Quantifier Float as Stranding: Evidence from Janitzio P'urhepecha.” Ms., University of California, Santa Cruz. http://people.ucsc.edu/ ezyman/p'urhepecha_q-float_paper.pdf 